\title{
Simulation of Steady-State and Dynamic Behaviour of a Plate Heat Exchanger
}

\author{
Mohammad Aqeel Saraireh \\ Department of Mechanical Engineering, Mutah University, Karak 61710, Jordan
}

Received: June 14, 2016 / Accepted: June 23, 2016 / Published: September 30, 2016.

\begin{abstract}
The present paper deals with both the steady-state and dynamic simulation of a plate heat exchanger, in counter-flow arrangement. A CFD (computational fluid dynamics) program FLUENT has been used to predict the temperature distribution in steady-state conditions in plate heat exchanger as well as fluid temperatures at exit of flow channels in transient condition. The results are presented for the heat exchanger, which is simulated according to the configuration of the plate heat exchanger used in the experiment. The simulated results obtained by the CFD model have been compared with the experimental data from the literature, which shows that the CFD model developed in this study is capable of predicting the steady-state and transient performance of the plate heat exchangers satisfactorily.
\end{abstract}

Key words: Heat exchanger, steady-state, CFD, simulation.

\section{Nomenclature}

$\begin{array}{ll}C_{p} & \text { Specific heat, } \mathrm{J} / \mathrm{kg} \cdot \mathrm{K} \\ E & \text { Energy, } \mathrm{J} \\ k_{\text {eff }} & \text { Effective thermal conductivity, } \mathrm{W} / \mathrm{m} \cdot \mathrm{K} \\ k_{f} & \text { Turbulent thermal conductivity, } \mathrm{W} / \mathrm{m} \cdot \mathrm{K} \\ k & \text { Turbulent kinetic energy, } \mathrm{m}^{2} / \mathrm{s}^{2} \\ P & \text { Pressure, } \mathrm{Pa} \\ S & \text { Modulus of the mean rate-of-strain tensor } \\ T & \text { Temperature, } \mathrm{K} \\ t & \text { Time, } \mathrm{s} \\ u & \text { Velocity }, \mathrm{m} / \mathrm{s}\end{array}$

Greek symbols

$\begin{array}{ll}\rho & \text { Density, } \mathrm{kg} / \mathrm{m}^{3} \\ \varepsilon & \text { Turbulent energy dissipation rate, } \mathrm{m}^{2} / \mathrm{s}^{3} \\ \nu & \text { Kinematic viscosity, } \mathrm{m}^{2} / \mathrm{s} \\ \mu & \text { Dynamic viscousity, } \mathrm{kg} / \mathrm{m} \cdot \mathrm{s} \\ \mu_{t} & \text { Turbulent viscousity, } \mathrm{kg} / \mathrm{m} \cdot \mathrm{s}\end{array}$

\section{Introduction}

Applications such as, power generation, manufacturing and space industries, as well as chemical reaction

Corresponding author: Mohammad Aqeel Saraireh, Ph.D., assistant professor, research fields: computational heat and fluid dynamics, heat exchangers. processes use plate heat exchangers due to their excellent heat transfer characteristic, easy fabrication and maintenance, low weight, excellent corrosion resistance, and cost competitiveness.

Dynamic behaviour of $\mathrm{n}$-channel two-fluid heat exchangers is studied in Refs. [1-4]. Zaleski and Tajszerki [5] presented the simulation of the dynamic performance for co-current plate heat exchangers. Khan et al. [6] presented the dynamic analysis of counter-current plate heat exchanger subjected to flow transient. Mehrabian [7] and Mehrabian and Poulter [8] developed analytical solutions for temperature distributions within a plate heat exchanger. The work was extended to focus on experimental approach for local pressure and local temperature measurements to understand the hydrodynamic and thermal characteristics of corrugated channels. Sharifi et al. [9] numerically analysed a plate heat exchanger with counter-flow arrangement in steady state and transient conditions. They used different numerical methods to predict the temperature distribution in steady state condition as well as fluid temperatures at exit of flow channels in transient condition. They also validated their numerical 
results by comparing them to experimental results in a test rig using specially designed flat plates. Srihari et al. [10] presented the dynamic behaviour of the single pass plate heat exchangers. Galeazzeo et al. [11] studied heat transfer in plate heat exchanger experimentally and numerically. Computational fluid dynamics tool was used to build the virtual prototype of the plate heat exchanger with four channels and flat plates. Temperature and velocity distribution for the channels were presented and compared with experimental data. Dwivedi and Das [12] investigated transient performance of the plate heat exchanger subjected to step flow disturbances. In the study by Vaisi et al. [13], a transient model of fin-and-tube heat exchangers was derived, and the variation of the temperatures of both fluid with time and position were obtained for a step change in the inlet temperatures of the water and air fluids. Yao et al. [14] developed transient response model for the water to air heat exchanger by using the state-space method. Dynamic responses of exit air and water temperature subjected to the disturbance of inlet water temperature were validated by dynamic response experiments. Singh et al. [15] investigated numerically transient behaviour of co-current parallel flow heat exchangers.

In the present study, three-dimensional numerical simulations using CFD (computational fluid dynamics) were carried out. Temperature distribution in case of steady-state and transient response of the plate heat exchanger was obtained.

\section{Numerical Simulation}

\subsection{Computational Domain}

The heat exchanger adopted in this investigation has the same dimensions and properties as those investigated by Sharifi et al. [9]. A general scheme of the counter flow, plate heat exchanger is shown in Fig. 1. The computational domain used in the simulation is detailed by Fig. 2 and Table 1 .

\subsection{Governing Equations}

The governing equations adopted by ANSYS
FLUENT are as follows [16]:

Continuity equation:

$$
\frac{\partial \rho}{\partial t}+\frac{\partial}{\partial x_{i}}\left(\rho u_{i}\right)=0
$$

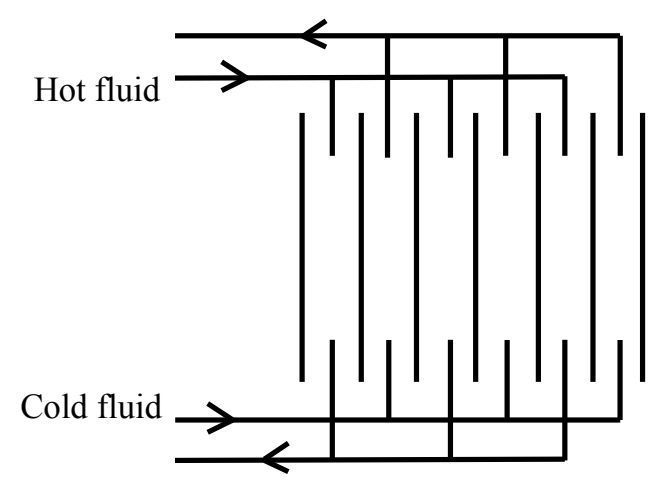

Fig. 1 Schematic drawing of the plate heat exchanger with 7 flat plates and 6 flow channels.

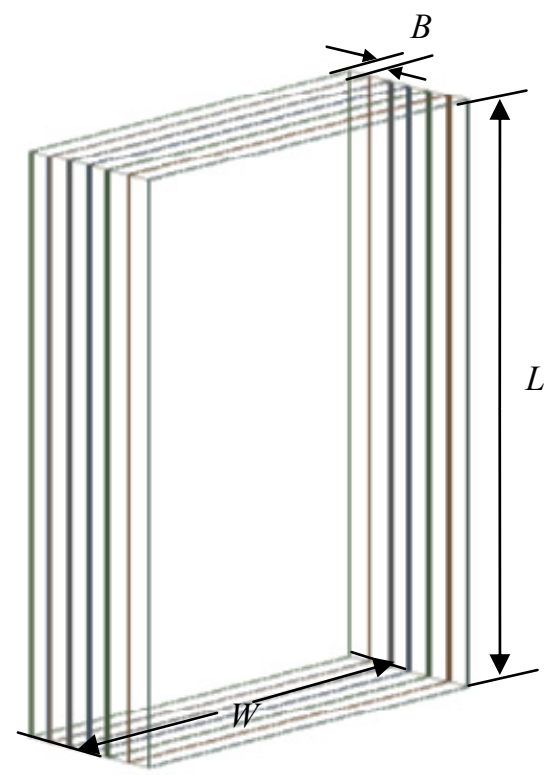

Fig. 2 Computational domain of simulated heat exchanger flow passages.

Table 1 Plate geometry and flow details.

\begin{tabular}{ll}
\hline Channel length $L$ & $0.33 \mathrm{~m}$ \\
Channel width $W$ & $0.09 \mathrm{~m}$ \\
Plate heat transfer area A & $0.0297 \mathrm{~m}^{2}$ \\
Channel gap $B$ & $0.005 \mathrm{~m}$ \\
Plate thickness & $0.0005 \mathrm{~m}$ \\
Hot water inlet temperature & $65^{\circ} \mathrm{C}$ \\
Cold water inlet temperature & $10^{\circ} \mathrm{C}$ \\
Hot water inlet mass flow rate & $0.045 \mathrm{~kg} / \mathrm{s}$ \\
Cold water inlet mass flow rate & $0.235 \mathrm{~kg} / \mathrm{s}$ \\
\hline
\end{tabular}


Momentum equation:

$$
\begin{aligned}
& \frac{\partial\left(\rho u_{i}\right)}{\partial t}+\frac{\partial}{\partial x_{j}}\left(\rho u_{i} u_{j}\right)=-\frac{\partial P}{\partial x_{i}}+ \\
& \frac{\partial}{\partial x_{j}}\left[\mu\left(\frac{\partial u_{i}}{\partial x_{j}}+\frac{\partial u_{j}}{\partial x_{i}}-\frac{2}{3} \delta_{i j} \frac{\partial u_{l}}{\partial x_{l}}\right)\right]+\frac{\partial}{\partial x_{j}}\left(-\rho \overline{u_{i}^{\prime} u_{j}^{\prime}}\right)
\end{aligned}
$$

where,

$$
-\rho \overline{u_{i}^{\prime} u_{j}^{\prime}}=\mu_{t}\left(\frac{\partial u_{i}}{\partial x_{j}}+\frac{\partial u_{j}}{\partial x_{i}}\right)-\frac{2}{3}\left(\rho k+\mu_{t} \frac{\partial u_{i}}{\partial x_{i}}\right) \delta_{i j}
$$

Transport equations adopted by the Realizable $k-\varepsilon$ model:

$$
\begin{aligned}
& \frac{\partial}{\partial t}(\rho k)+\frac{\partial}{\partial x_{j}}\left(\rho k u_{j}\right)= \\
& \frac{\partial}{\partial x_{j}}\left[\left(\mu+\frac{\mu_{t}}{\sigma_{k}}\right) \frac{\partial k}{\partial x_{j}}\right]+\mu_{t} S^{2}-\rho \varepsilon
\end{aligned}
$$

and

$$
\begin{aligned}
& \frac{\partial}{\partial t}(\rho \varepsilon)+\frac{\partial}{\partial x_{j}}\left(\rho \varepsilon u_{j}\right)= \\
& \frac{\partial}{\partial x_{j}}\left[\left(\mu+\frac{\mu_{t}}{\sigma_{\varepsilon}}\right) \frac{\partial \varepsilon}{\partial x_{j}}\right]-\rho C_{2} \frac{\varepsilon^{2}}{k+\sqrt{v \varepsilon}}
\end{aligned}
$$

where,

$$
\begin{aligned}
& \mu_{t}=\rho C_{\mu} \frac{k^{2}}{\varepsilon}, S=\sqrt{2 S_{i j} S_{i j}}, \\
& \sigma_{k}=1, \sigma_{\varepsilon}=1.2, C_{2}=1.9
\end{aligned}
$$

Energy equation:

$$
\frac{\partial}{\partial t}(\rho E)+\frac{\partial}{\partial x_{i}}\left(u_{i}(\rho E+p)\right)=\frac{\partial}{\partial x_{i}}\left(k_{e f f} \frac{\partial T}{\partial x_{i}}\right)
$$

where, $\mathrm{E}$ is the total energy and $k_{\text {eff }}=k+k_{t}$ is the effective conductivity, including the turbulent thermal conductivity $k_{t}$.

Energy transport equation in the solid region:

$$
\frac{\partial}{\partial t}\left(\rho c_{p} T\right)=\frac{\partial}{\partial x_{i}}\left(k_{s} \frac{\partial T}{\partial x_{i}}\right)
$$

\subsection{Boundary Conditions}

The velocity boundary condition is used to define the velocity magnitude and direction of the water at the hot and cold inlets of the heat exchangers. The inlet temperature is also required at this boundary. The pressure outlet condition is used to model the flow conditions at the outlets of the heat exchanger.

All solid surfaces of the heat exchanger are modelled using the wall boundary condition. Because the wall zone here is a two-side wall, which is a wall that forms the interface between two regions such as the fluid/solid interface, FLUENT enables the two sides of the wall to be coupled, prompting the solver to calculate the heat transfer directly from the solution in the adjacent cells. All other solid surfaces are defined as an adiabatic wall by setting a zero heat flux condition.

\subsection{Solver}

The governing equations for the conservation of mass, momentum, and energy equations were solved using commercial software FLUENT. The SIMPLE (semi-implicit method for pressure linked equation) algorithm was used for the calculation of the pressure and the velocity, which were needed for the solution of energy equation. The simulation was also solved using the Realizable $k-\varepsilon$ turbulence model with enhanced wall treatment.

Tests were conducted to verify the grid independency of the results. Simulations were performed for different grids size, until the results were consistent. The numerical domain consisted of 200,000 elements and a second-order upwind differencing scheme was used at all interior grid points.

\section{Results and Discussion}

To validate the model, simulated data were compared with the experimental data reported by Sharifi et al. [9]. The plate heat exchanger geometric parameters and flow details listed in Table 1 were incorporated in the present model for the validations.

The simulated data from the present modelling in steady state condition were compared with the 
temperature distribution of flow in the channels of plate heat exchanger reported by Sharifi et al. [9].

The variations of hot water temperature in channels 1, 3 and 5 with respect to channel length are shown in Figs. 3-5. As expected, the numerical simulations indicated a decreasing hot water temperature along the flow direction due to heat transfer from hot to the cold water. From these figures, it can be seen that, there is a good agreement between the simulation results of presented model and the experimental results of Sharifi et al. [9].

The distributions of temperature for cold water along channels 2, 4 and 6 are shown in Figs. 6-8. These figures indicate that, the temperature of cold water increased along the flow direction. It can be concluded from Figs. 6-8 that the simulation results are reasonably in good agreement with the experimental data.

Simulations have been carried out to predict the plate heat exchanger behavior, in terms of outlet

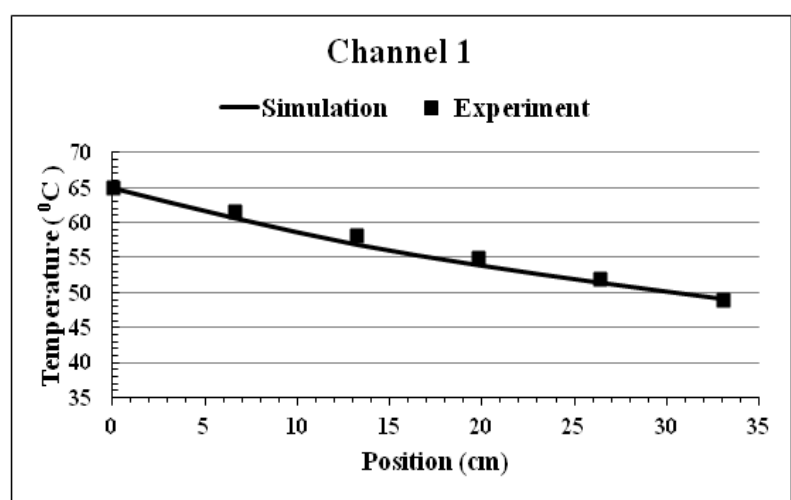

Fig. 3 Comparison of experimental and simulated hot temperature distribution in channel 1.

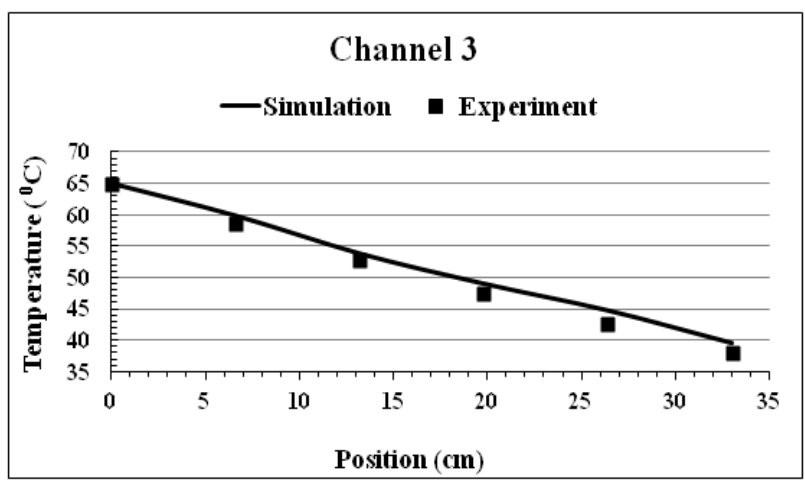

Fig. 4 Comparison of experimental and simulated hot temperature distribution in channel 3.

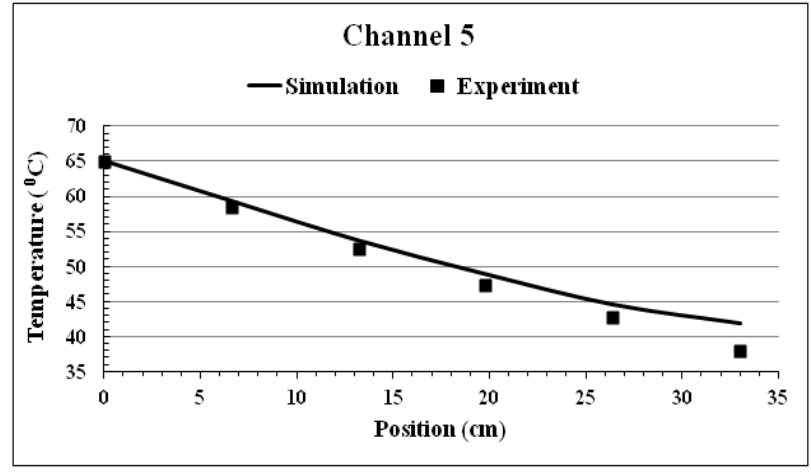

Fig. 5 Comparison of experimental and simulated hot temperature distribution in channel 5.

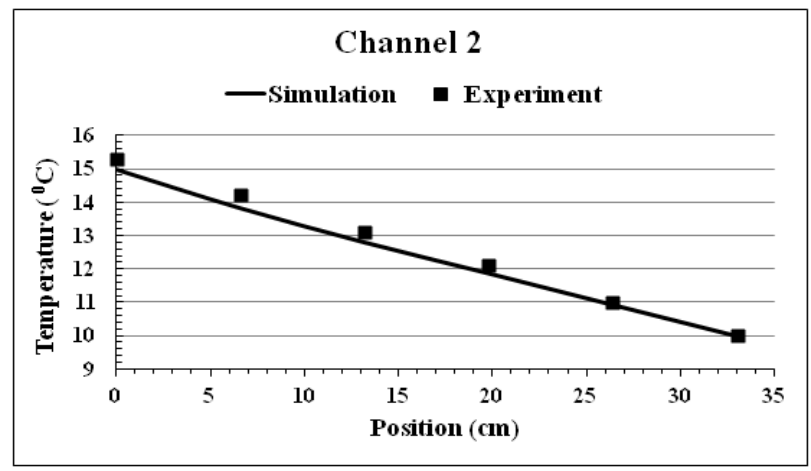

Fig. 6 Comparison of experimental and simulated cold temperature distribution in channel 2.

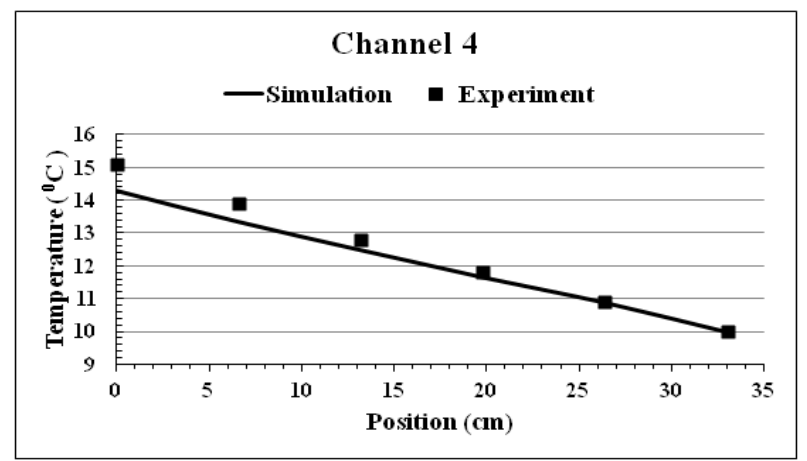

Fig. 7 Comparison of experimental and simulated cold temperature distribution in channel 4.

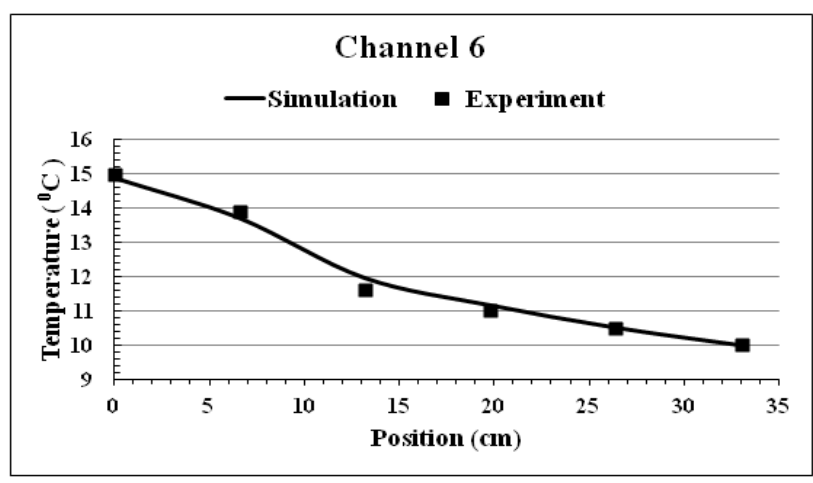

Fig. 8 Comparison of experimental and simulated cold temperature distribution in channel 6. 
temperatures of the two fluids, for transient operating conditions. For example, it is useful to determine the response of the system to inputs changes of the inlet temperatures and the variations of flow rates.

Figs. 9 and 10 show the response of temperatures when hot fluid flow rate is $38 \mathrm{~cm}^{3} / \mathrm{s}$, cold fluid flow rate is $35 \mathrm{~cm}^{3} / \mathrm{s}$, and hot fluid step temperature is $56^{\circ} \mathrm{C}$.

To check the validity of the simulation model the predicted results have been compared with the experimental data. Figs. 9 and 10 show the comparison between the simulation and experimental results of Sharifi et al. [9] run 1 for the outlet temperatures of hot and cold water. It can be observed from the figures that there is a good agreement between model and experimental results.

Figs. 11 and 12 show the comparison of the model predictions and the experimental results of Sharifi et al. [9] for run number 2 when hot fluid flow rate is 40 $\mathrm{cm}^{3} / \mathrm{s}$, cold fluid flow rate is $90 \mathrm{~cm}^{3} / \mathrm{s}$, and hot fluid step temperature is $56{ }^{\circ} \mathrm{C}$.

It can be clearly observed from the figures that represent the flow transient, both the outlet

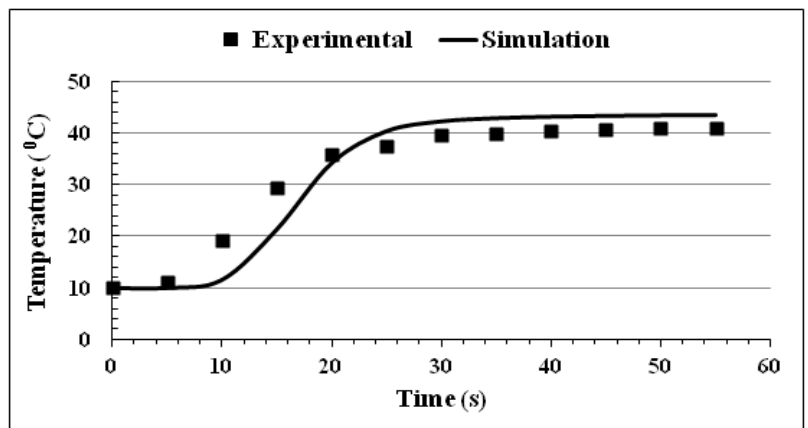

Fig. 9 Comparison of experimental and simulated outlet hot temperature for run number 1 .

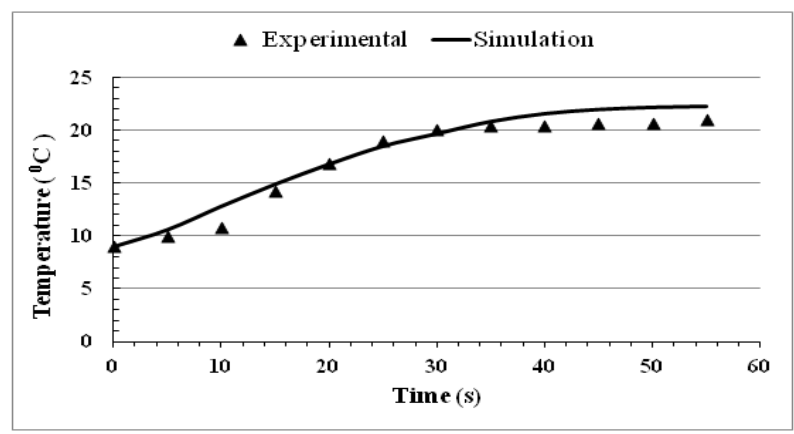

Fig. 10 Comparison of experimental and simulated outlet cold temperature for run number 1.

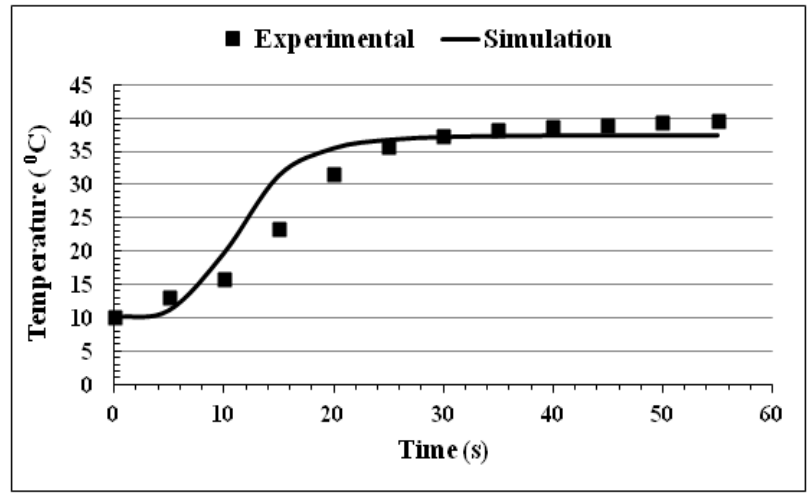

Fig. 11 Comparison of experimental and simulated outlet hot temperature for run number 2 .

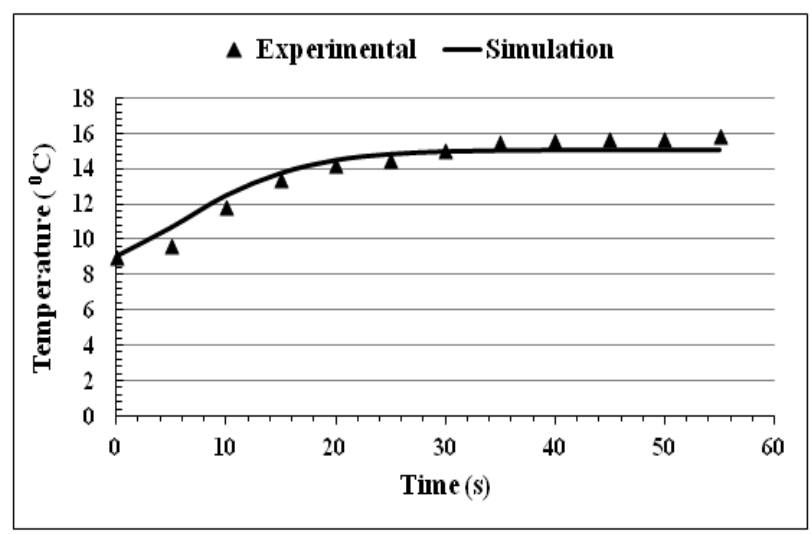

Fig. 12 Comparison of experimental and simulated outlet cold temperature for run number 2 .

temperatures are increased. They go on increasing till a new steady state is achieved. As depicted in Figs. 11 and 12, the obtained CFD results show a good agreement with the experimental data.

\section{Conclusions}

Steady-state and dynamic behavior of counter flow heat exchanger has been investigated using CFD. Governing equations are solved using FLUENT software in order to get the steady state temperature distribution along the channels of the plate heat exchanger. Taking this temperature distribution as initial condition, governing equations for the flow transient have been solved. To check the validity of the simulation, the results of the CFD model have been compared to the experiment from the literature. The comparison indicates a good agreement, which validates the suggested model for steady state and transient flow in plate heat exchangers. Results also 
indicate the allowable time duration required for the control system to bring back a plate heat exchanger to steady state.

\section{References}

[1] Correa, D. J., and Marchetti, J. L. 1987. "Dynamic Simulation of Shell-and-Tube Heat Exchangers." Heat Transfer Engineering 8 (1): 50-9.

[2] Lakshmanan, C. C., and Potter, O. E. 1990. "Dynamic Simulation of Plate Heat Exchangers." International Journal of Heat and Mass Transfer 33 (5): 995-1002.

[3] Roetzel, W., and Xuan, Y. 1992. "Transient Behaviour of Multipass Shell-and-Tube Heat Exchangers." International Journal of Heat and Mass Transfer 35 (3): 703-10.

[4] Roppo, M. N., and Ganl, E. N. 1983. "Time-Dependent Heat Exchanger Modeling." Heat Transfer Engineering 4 (2): 42-6.

[5] Zaleski, T., and Tajszerski, J. 1980. "Dynamics of the Plate Heat Exchangers." Computations in the Design and Erection of Chemical Plants 2 (September): 3-5.

[6] Khan, A. R., Baker, N. S., and Wardle, A. P. 1988. "The Dynamic Characteristics of a Countercurrent Plate Heat Exchanger." International Journal of Heat and Mass Transfer 31 (6): 1269-78.

[7] Mehrabian, M. A. 1998. "Influence of Overall Heat Transfer Coefficient on Performance of Plate Heat Exchangers." Institute of Mathematics and Its Applications Conference Series 66: 233-42.

[8] Mehrabian, M. A., and Poulter, R. 2000. "Hydrodynamics and Thermal Characteristics of Corrugated Channels: Computational Approach." Applied Mathematical
Modelling 24 (5): 343-64.

[9] Sharifi, F., Narandji, M. R. G., and Mehravaran, K. 1995. "Dynamic Simulation of Plate Heat Exchangers." International Communications in Heat and Mass Transfer 22 (2): 213-25.

[10] Srihari, N., Rao, B. P., Sunden, B., and Das, S. K. 2005. "Transient Response of Plate Heat Exchangers Considering Effect of Flow Maldistribution." International Journal of Heat and Mass Transfer 48 (15): 3231-43.

[11] Galeazzo, F. C. C., Miura, R. Y., Gut, J. A. W., and Tadini, C. C. 2006. "Experimental and Numerical Heat Transfer in a Plate Heat Exchanger." Chemical Engineering Science 61 (21): 7133-8.

[12] Dwivedi, A. K., and Das, S. K. 2007. "Dynamics of Plate Heat Exchangers Subject to Flow Variations." International Journal of Heat and Mass Transfer 50 (13): 2733-43.

[13] Vaisi, A., Talebi, S., and Esmaeilpour, M. 2011. "Transient Behavior Simulation of Fin-and-Tube Heat Exchangers for the Variation of the Inlet Temperatures of Both Fluids." International Communications in Heat and Mass Transfer 38 (7): 951-7.

[14] Yao, Y., Huang, M., Mo, J., and Dai, S. 2013. "State-Space Model for Transient Behavior of Water-to-Air Surface Heat Exchanger." International Journal of Heat and Mass Transfer 64 (September): 173-92.

[15] Singh, S. K., Mishra, M., and Jha, P. K. 2014. "Transient Behavior of Co-current Parallel Flow Three-Fluid Heat Exchanger." International Communications in Heat and Mass Transfer 52 (March): 46-50.

[16] Ansys Fluent V14.0 Theory Guide, 2011. 